\title{
Aphasic seizures in patients with temporopolar and anterior temporobasal lesions: A video-EEG study
}

\author{
Rafael Toledano , Adolfo Jiménez-Huete , Irene García-Morales ,Pablo Campo , Claudia Poch , \\ Bryan A. Strange , Antonio Gil-Nagel
}

\begin{abstract}
A B S T R A C T
Studies of patients with temporal lobe epilepsy provide few descriptions of seizures that arise in the temporopolar and the anterior temporobasal brain region. Based on connectivity, it might be assumed that the semiology of these seizures is similar to that of medial temporal lobe epilepsy. However, accumulating evidence suggests that the anterior temporobasal cortex may play an important role in the language system, which could account for particular features of seizures arising here. We studied the electroclinical features of seizures in patients with circumscribed temporopolar and temporobasal lesions in order to identify specific features that might differentiate them from seizures that originate in other temporal areas. Among 172 patients with temporal lobe seizures registered in our epilepsy unit in the last 15 years, $15(8.7 \%)$ patients had seizures caused by temporopolar or anterior temporobasal lesions (11 left-sided lesions). The main finding in our study is that patients with left-sided lesions had aphasia during their seizures as the most prominent feature. In addition, while all patients showed normal to high intellectual functioning in standard neuropsychological testing, semantic impairment was found in a subset of 9 patients with left-sided lesions. This case series demonstrates that aphasic seizures without impairment of consciousness can result from small, circumscribed left anterior temporobasal and temporopolar lesions. Thus, the presence of speech manifestation during seizures should prompt detailed assessment of the structural integrity of the basal surface of the temporal lobe in addition to the evaluation of primary language areas.
\end{abstract}

\section{Introduction}

Studies of patients with temporal lobe epilepsy provide few descriptions of seizures that arise in the temporopolar and the anterior temporobasal areas. Based on connectivity and anatomy, it might be assumed that the semiology of seizures arising in these two brain areas is similar to that of medial temporal lobe epilepsy. However, accumulating evidence suggests that the temporal pole and the temporal basal area play an important functional role in the language system, which could account for specific features of seizures arising here. Electrophysiological studies demonstrated that surface electrical stimulation during epilepsy surgery of a basal temporal language area (BTLA) produces a range of speech disturbances [1-3]. A combination of neuroimaging and neuropsychological studies has subsequently improved our understanding of the functional role of these dominant anterior temporal lobe areas in language [4-6]. In light of these data, the aim of this study was to characterize the electroclinical features of seizures originating in the anterior temporobasal and temporopolar regions.

\section{Material and methods}

\subsection{Patient selection}

All patients with temporal lobe epilepsy admitted to our epilepsy unit for presurgical evaluation between January 1998 and February 2013 were reviewed. Inclusion criteria for our analyses were the following: 1. a characteristic regional ictal pattern over the ipsilateral temporal lobe on scalp EEG and 2. a circumscribed lesion located at the temporal pole or the temporal basal region on MRI. Patients with dual pathology (temporobasal lesions and hippocampal sclerosis), 
lesions extending to other temporal regions, or only secondary generalized tonic-clonic (SGTC) seizures recorded were excluded.

\subsection{Video-EEG investigation}

All patients had undergone long-term surface video-EEG recordings. Seizure semiology was assessed by reviewing the video recordings and classified by three experienced epileptologists according to the criteria of the International League Against Epilepsy (ILAE) and the Glossary of Descriptive Terminology for Ictal Semiology $[7,8]$. Language function was tested repeatedly throughout the ictal and the postictal period until fully recovered. Language impairment was assessed according to each patient's spontaneous speech, comprehension to common verbal and written commands, and response to directed tests of naming, repetition, and reading. Speech phenomena were correlated with EEG findings to determine whether they were ictal or postictal. The type of language impairment was classified according to established criteria [9]. Maintenance of ictal consciousness was assumed if orientation behavior and postictal memory were intact, i.e., the patient was able to turn towards the examiner on sensory stimulation during the seizure and could recall what happened around him/her following seizure termination [10]. Other parameters analyzed to describe seizure semiology were the presence of aura, staring, behavioral arrest, oral automatisms, manual and pedal automatisms, upper limb dystonia, head deviation, hypermotor automatisms, and postictal nose wiping.

\subsection{Brain imaging}

In all patients, 3-Tesla brain MRI was performed. All imaging protocols included volume acquisition, $\mathrm{T} 1$ - and $\mathrm{T} 2$-weighted sequences, and fluid-attenuated inversion recovery (FLAIR) sequences.

\subsection{Neuropsychological assessment}

Most patients underwent neuropsychological testing. We applied a standardized neuropsychological battery that included verbal and performance IQ indices of intellectual function from the Wechsler Adult Intelligence Scale-III. Verbal memory functioning was assessed using scores from the immediate and delayed primary subtests of the Wechsler Memory Scale-III (WMS-III). Nonverbal memory (Rey figure and Benton test to shape visual screening), visual-perceptive function (Hooper and Benton test), and executive functions (trail making test $A$ and B and Stroop test) were also assessed in most patients. Furthermore, as numerous neuropsychological and neuroimaging studies have indicated a prominent role of anterobasal temporal regions in naming and semantic memory $[11,12]$, we focused neuropsychological testing on these processes in a subsample of 9 patients with left temporabasal and temporopolar lesions. Ten matched healthy controls were also enrolled and assessed. Patients and controls did not differ in terms of age or in level of education. Semantic tasks included a) two picture-naming tasks, the Philadelphia naming test, and the Cambridge 64-item naming task [13]; b) a measure of visual semantic associative knowledge (Camel and Cactus test); and c) a category fluency test. The last three tests were extracted from the Cambridge Semantic Battery [14].

\section{Results}

\subsection{Study population}

Of a total of 172 patients with temporal lobe seizures registered in our epilepsy unit, 15 (8.7\%, 7 females) patients met our inclusion criteria (Table 1). All patients were right-handed. Age of epilepsy onset ranged from 12 to 40 years (mean: 23.5 years). No patient reported risk factors for epilepsy or family history of seizures. At the time of video-EEG evaluation (mean: 36.9 years, range: $16-59$ years), all patients had drug-refractory epilepsy with seizure frequency ranging from daily seizures to a minimum of one seizure per month. Before video-EEG analysis, seizures of most patients were initially classified as complex partial seizures, since many of them were unable to recall what had been said during the seizure and witnesses described that they looked confused and could not follow their commands. Despite this, when asked, most of them were able to recall details of what happened around their seizures, and those patients with left temporal lesions (Table 1) described some kind of inability to understand what other people said and to generate spoken responses. Ten patients had also suffered infrequent SGTC seizures since the onset of their epilepsy.

\subsection{Clinical seizure analysis}

A total of 49 seizures were available for review. The number of recorded seizures per patient ranged from 1 to 7 (mean: 3.26). According to the ictal and the postictal semiology, we could distinguish two groups of patients.

The most prominent feature of seizures in patients with left-sided lesions was alteration of language. Language manifestations during the ictal period usually consisted in combined expressive and receptive deficits. The patients typically remained quiet throughout this period or just uttered isolated words or short sentences, such as "no", "yes", "wait", or "I feel bad", in response to verbal commands. Two patients also had milder seizures with less impairment of expressive function (Table 1). Language comprehension was impaired in all patients, as shown by an inability to follow verbal or written commands during the ictal period. Language deficits continued throughout the postictal period in most patients, and they were characterized by a gradual recovery of verbal fluency and then comprehension. Reduced verbal fluency, impairment of verbal and written comprehension, dysnomia, semantic paraphasias, and preserved repetition were the most common findings in this period. Once language function had recovered, all patients could recall details of their seizures and reported an inability to speak and comprehend. Ictal nonverbal behavior was not impaired; all of them were alert and turned towards the examiner on verbal request, trying to interact with the examiner and follow his commands. Other ictal features, mainly limited to subtle oral and/or hand automatisms, were found in 6 patients.

In contrast to patients with left-sided lesions, ictal speech in patients with right temporobasal lesions was preserved and consisted in fluent, well-articulated, and linguistically correct sentences, either spontaneously or in response to verbal and written commands. All patients reported auras followed by psychic symptoms, such as a feeling of familiarity and "weirdness" and could recall what happened throughout their seizures. In addition, two patients showed motor restlessness, and two other patients had subtle oral automatisms in the ictal phase.

\subsection{Electrophysiological seizure analysis}

Electroencephalography showed interictal epileptiform activity localized to the temporal lobe in all 15 patients. This was unilateral in 13 patients and bilateral in 2, although in these 2 cases interictal epileptiform activity was highly predominant over the temporal lobe with the lesion identified on MRI. No extratemporal epileptic discharges were seen in any patient. All patients had unilateral ictal regional anterior temporal patterns on surface EEG, characterized by rhythmical theta/delta activity that was always evident within the first 20 s of clinical onset. Stereoelectroencephalography in two patients with left-sided lesions confirmed an epileptogenic zone circumscribed to the temporal pole.

\subsection{Neuroimaging}

Discrete lesions distributed in different areas of the temporobasal region were found in brain MRI studies of all patients (11 left side, 4 right 
Table 1

Patient and brain imaging characteristics.

\begin{tabular}{|c|c|c|c|c|c|c|c|}
\hline Patient & $\begin{array}{l}\text { Age at } \\
\text { evaluation/ } \\
\text { sex }\end{array}$ & $\begin{array}{l}\text { Age at } \\
\text { seizure } \\
\text { onset }\end{array}$ & $\begin{array}{l}\text { No. of } s z \\
\text { recorded } \\
\text { Duration }\end{array}$ & Language manifestations & $\begin{array}{l}\text { Type of aura } \\
\text { Other semiology }\end{array}$ & $\begin{array}{l}\text { Type of lesion } \\
\text { Location }^{\mathrm{a}}\end{array}$ & Outcome \\
\hline 1 & $25 \mathrm{y} / \mathrm{M}$ & $19 y$ & $\begin{array}{l}3 \mathrm{sz} \\
76-90 \mathrm{~s}\end{array}$ & $\begin{array}{l}\text { Ictal: global aphasia ( } 1 \text { st and } 2 \text { nd sz) } \\
\text { Reduced verbal fluency with } \\
\text { semantic paraphasias (3rd sz) } \\
\text { Postictal: MTA }\end{array}$ & $\begin{array}{l}\text { Cephalic aura } \\
\text { Subtle mouth } \\
\text { automatisms }\end{array}$ & $\begin{array}{l}\text { Encephalocele } \\
\text { Left temporobasal pole }\end{array}$ & $\begin{array}{l}\text { Left anterobasal } \\
\text { lobectomy } \\
\text { Sz-free }\end{array}$ \\
\hline 2 & $42 \mathrm{y} / \mathrm{M}$ & $40 y$ & $\begin{array}{l}4 s z \\
41-48 s\end{array}$ & $\begin{array}{l}\text { Ictal: global aphasia } \\
\text { Postictal: no postictal period }\end{array}$ & $\begin{array}{l}\text { Cephalic aura } \\
\text { None }\end{array}$ & $\begin{array}{l}\text { Encephalocele } \\
\text { Left temporobasal pole }\end{array}$ & Sz-free on drugs \\
\hline 3 & $39 \mathrm{y} / \mathrm{F}$ & $32 \mathrm{y}$ & $\begin{array}{l}2 \mathrm{sz} \\
149-157 \mathrm{~s}\end{array}$ & $\begin{array}{l}\text { Ictal: global aphasia } \\
\text { Postictal: MTA }\end{array}$ & $\begin{array}{l}\text { Epigastric aura } \\
\text { None }\end{array}$ & $\begin{array}{l}\text { Encephalocele } \\
\text { Left temporobasal pole }\end{array}$ & $\begin{array}{l}\text { Declined surgery } \\
\text { Not controlled }\end{array}$ \\
\hline 4 & $35 \mathrm{y} / \mathrm{F}$ & $17 y$ & $\begin{array}{l}4 \mathrm{sz} \\
20-70 \mathrm{~s}\end{array}$ & $\begin{array}{l}\text { Ictal: global aphasia } \\
\text { Postictal: MTA }\end{array}$ & $\begin{array}{l}\text { Unspecific aura } \\
\text { None }\end{array}$ & $\begin{array}{l}\text { Focal cortical dysplasia } \\
\text { Left temporobasal pole }\end{array}$ & $\begin{array}{l}\text { Left anterobasal } \\
\text { lobectomy }^{\mathrm{b}}\end{array}$ \\
\hline 5 & $34 \mathrm{y} / \mathrm{F}$ & $36 y$ & $\begin{array}{l}2 s z \\
80-83 s\end{array}$ & $\begin{array}{l}\text { Ictal: global aphasia } \\
\text { Postictal: no postictal period }\end{array}$ & $\begin{array}{l}\text { Epigastric aura } \\
\text { Subtle mouth } \\
\text { automatisms }\end{array}$ & $\begin{array}{l}\text { Encephalocele } \\
\text { Left temporobasal pole }\end{array}$ & $\begin{array}{l}\text { Declined surgery } \\
\text { Not controlled }\end{array}$ \\
\hline 6 & $59 \mathrm{y} / \mathrm{F}$ & $26 y$ & $\begin{array}{l}5 \mathrm{sz} \\
42-58 \mathrm{~s}\end{array}$ & $\begin{array}{l}\text { Ictal: global aphasia } \\
\text { Postictal: MTA } \\
\text { No postictal period (3rd sz) }\end{array}$ & $\begin{array}{l}\text { Unspecific aura } \\
\text { Subtle facial } \\
\text { grimacing }\end{array}$ & $\begin{array}{l}\text { Cavernous angioma } \\
\text { Left parahippocampal gyrus } \\
2.976 \mathrm{~cm}\end{array}$ & $\begin{array}{l}\text { Declined surgery } \\
\text { Not controlled }\end{array}$ \\
\hline 7 & $31 \mathrm{y} / \mathrm{M}$ & $20 y$ & $\begin{array}{l}3 \mathrm{sz} \\
40-120 \mathrm{~s}\end{array}$ & $\begin{array}{l}\text { Ictal: global aphasia } \\
\text { Postictal: MTA }\end{array}$ & $\begin{array}{l}\text { Cephalic aura } \\
\text { None }\end{array}$ & $\begin{array}{l}\text { Cavernous angioma } \\
\text { Left parahippocampal and } \\
\text { fusiform gyri } \\
4.420 \mathrm{~cm}\end{array}$ & $\begin{array}{l}\text { Declined surgery } \\
\text { Not controlled }\end{array}$ \\
\hline 8 & $55 \mathrm{y} / \mathrm{M}$ & $33 y$ & $\begin{array}{l}3 \mathrm{sz} \\
52-65 \mathrm{~s}\end{array}$ & $\begin{array}{l}\text { Ictal: global aphasia } \\
\text { Postictal: MTA }\end{array}$ & $\begin{array}{l}\text { Unspecific aura } \\
\text { Mouth automatisms }\end{array}$ & $\begin{array}{l}\text { Cavernous angioma } \\
\text { Left temporobasal pole }\end{array}$ & $\begin{array}{l}\text { Lesionectomy } \\
\text { Sz-free }\end{array}$ \\
\hline 9 & $26 \mathrm{y} / \mathrm{F}$ & $12 y$ & $\begin{array}{l}2 \mathrm{sz} \\
33-128 \mathrm{~s}\end{array}$ & $\begin{array}{l}\text { Ictal: global aphasia (1st sz) } \\
\text { Reduced verbal fluency and } \\
\text { semantic paraphasias, (2nd sz) } \\
\text { Postictal: MTA } \\
\text { No postictal period (2nd sz) }\end{array}$ & $\begin{array}{l}\text { Cephalic aura } \\
\text { None }\end{array}$ & $\begin{array}{l}\text { Focal cortical atrophy } \\
\text { Left temporobasal pole }\end{array}$ & $\begin{array}{l}\text { Declined surgery } \\
\text { Not controlled }\end{array}$ \\
\hline 10 & $53 \mathrm{y} / \mathrm{F}$ & $20 y$ & $\begin{array}{l}5 \mathrm{sz} \\
85-140 \mathrm{~s}\end{array}$ & $\begin{array}{l}\text { Ictal: global aphasia } \\
\text { Postictal: MTA }\end{array}$ & $\begin{array}{l}\text { Epigastric aura } \\
\text { Right hand } \\
\text { automatisms }\end{array}$ & $\begin{array}{l}\text { Focal cortical atrophy } \\
\text { Left temporobasal pole }\end{array}$ & $\begin{array}{l}\text { Declined surgery } \\
\text { Not controlled }\end{array}$ \\
\hline 11 & $32 \mathrm{y} / \mathrm{M}$ & $23 y$ & $\begin{array}{l}1 \mathrm{sz} \\
70 \mathrm{~s}\end{array}$ & $\begin{array}{l}\text { Ictal: global aphasia } \\
\text { Postictal: MTA }\end{array}$ & $\begin{array}{l}\text { None } \\
\text { None }\end{array}$ & $\begin{array}{l}\text { Encephalocele } \\
\text { Left temporobasal pole }\end{array}$ & $\begin{array}{l}\text { Awaiting surgery } \\
\text { Not controlled }\end{array}$ \\
\hline 12 & $42 y / F$ & $14 y$ & $\begin{array}{l}4 \mathrm{sz} \\
35-50 \mathrm{~s}\end{array}$ & $\begin{array}{l}\text { Ictal: initial vocalization } \\
\text { Preserved ictal speech } \\
\text { Postictal: no postictal period }\end{array}$ & $\begin{array}{l}\text { Epigastric aura } \\
\text { Motor restlessness }\end{array}$ & $\begin{array}{l}\text { Encephalocele } \\
\text { Right temporobasal pole }\end{array}$ & $\begin{array}{l}\text { Right anterobasal } \\
\text { lobectomy } \\
\text { Sz-free }\end{array}$ \\
\hline 13 & $29 \mathrm{y} / \mathrm{M}$ & $15 y$ & $\begin{array}{l}3 \mathrm{sz} \\
50-83 \mathrm{~s}\end{array}$ & $\begin{array}{l}\text { Ictal: preserved ictal speech } \\
\text { Postictal: no postictal period }\end{array}$ & $\begin{array}{l}\text { Cephalic aura } \\
\text { Subtle mouth } \\
\text { automatisms }\end{array}$ & $\begin{array}{l}\text { Ganglioglioma } \\
\text { Right parahippocampal gyrus } \\
1.991 \mathrm{~cm}\end{array}$ & $\begin{array}{l}\text { Right anterobasal } \\
\text { lobectomy } \\
\text { Sz-free }\end{array}$ \\
\hline 14 & $16 \mathrm{y} / \mathrm{M}$ & $13 y$ & $\begin{array}{l}7 \mathrm{sz} \\
20-45 \mathrm{~s}\end{array}$ & $\begin{array}{l}\text { Ictal: preserved ictal speech } \\
\text { Postictal: no postictal period }\end{array}$ & $\begin{array}{l}\text { Déjà-vu } \\
\text { Fearful expression, } \\
\text { motor restlessness }\end{array}$ & $\begin{array}{l}\text { Ganglioglioma } \\
\text { Right parahippocampal gyrus } \\
3.173 \mathrm{~cm}\end{array}$ & $\begin{array}{l}\text { Right anterobasal } \\
\text { lobectomy } \\
\text { Sz-free }\end{array}$ \\
\hline 15 & $36 \mathrm{y} / \mathrm{M}$ & $33 y$ & $\begin{array}{l}1 \mathrm{sz} \\
32 \mathrm{~s}\end{array}$ & $\begin{array}{l}\text { Ictal: preserved ictal speech } \\
\text { Postictal: no postictal period }\end{array}$ & $\begin{array}{l}\text { Déjà-vu } \\
\text { Subtle mouth } \\
\text { automatisms }\end{array}$ & $\begin{array}{l}\text { Cavernous angioma } \\
\text { Right fusiform gyrus } \\
2.995 \mathrm{~cm}\end{array}$ & $\begin{array}{l}\text { Lesionectomy } \\
\text { Sz-free }\end{array}$ \\
\hline
\end{tabular}

y: years; sz: seizure(s); s: seconds; MTA: mixed transcortical aphasia.

a Distance from the tip of the temporal pole to the anterior border of the lesion.

b This patient has just been operated on. Pathology confirmed a mild malformation of cortical development.

side) (Table 1). Lesions involved the basal temporopolar cortex, the anterior parahippocampal gyrus, the inferior temporal gyrus, or the anterior fusiform gyrus. In only one patient, the lesion involved both the left parahippocampal and fusiform gyri. Of note, brain MRI scans were initially reported as normal in 8 patients in whom lesions were eventually recognized after review of MR images guided by EEG findings and ictal semiology (Fig. 1).

\subsection{Neuropsychological assessment}

Standardized neuropsychological testing was available in 13 patients ( 9 patients with left lesions). Patients showed normal to high intellectual functioning in both verbal and pictorial domains, as well as normal verbal memory performance (Table 2). However, further neuropsychological assessment in 9 patients with left temporal lesions revealed subtle yet significant deficits (Table 2). Analysis was performed using Kruskal-Wallis one-way ANOVA. Although no impairment was observed in confrontation naming on the Cambridge 64-item naming task, patients performed worse than controls on the 175-item
Philadelphia naming test $\left(\chi^{2}=5.61, \mathrm{p}<.05\right)$. Semantic function was impaired both at the level of visual associative matching $\left(\chi^{2}=5.25\right.$, $\mathrm{p}<.05$ ) (Camel and Cactus test) and in category fluency. Patients showed impaired fluency in the two living categories (birds and breeds of dogs) $\left(\chi^{2}=6.84, \mathrm{p}<.01 ; \chi^{2}=7.05, \mathrm{p}<.01\right.$, respectively) but not for the man-made category (boats) $\left(\chi^{2}=0.06, \mathrm{p}>.05\right)$.

\subsection{Outcome}

All patients were evaluated for epilepsy surgery. Left-hemisphere language dominance was confirmed by Wada test in 7 patients who eventually underwent surgery (Table 1): 2 lesionectomies (resection of a cavernous angioma guided by electrocorticography) and 5 anterobasal temporal lobectomies with hippocampal sparing. Six patients became seizure-free since surgery (follow-up: 2 to 8 years), and another patient has just been operated on. In 8 patients that did not undergo surgery, seizures were only controlled in one patient. Seven patients who rejected surgery were not controlled after at least 


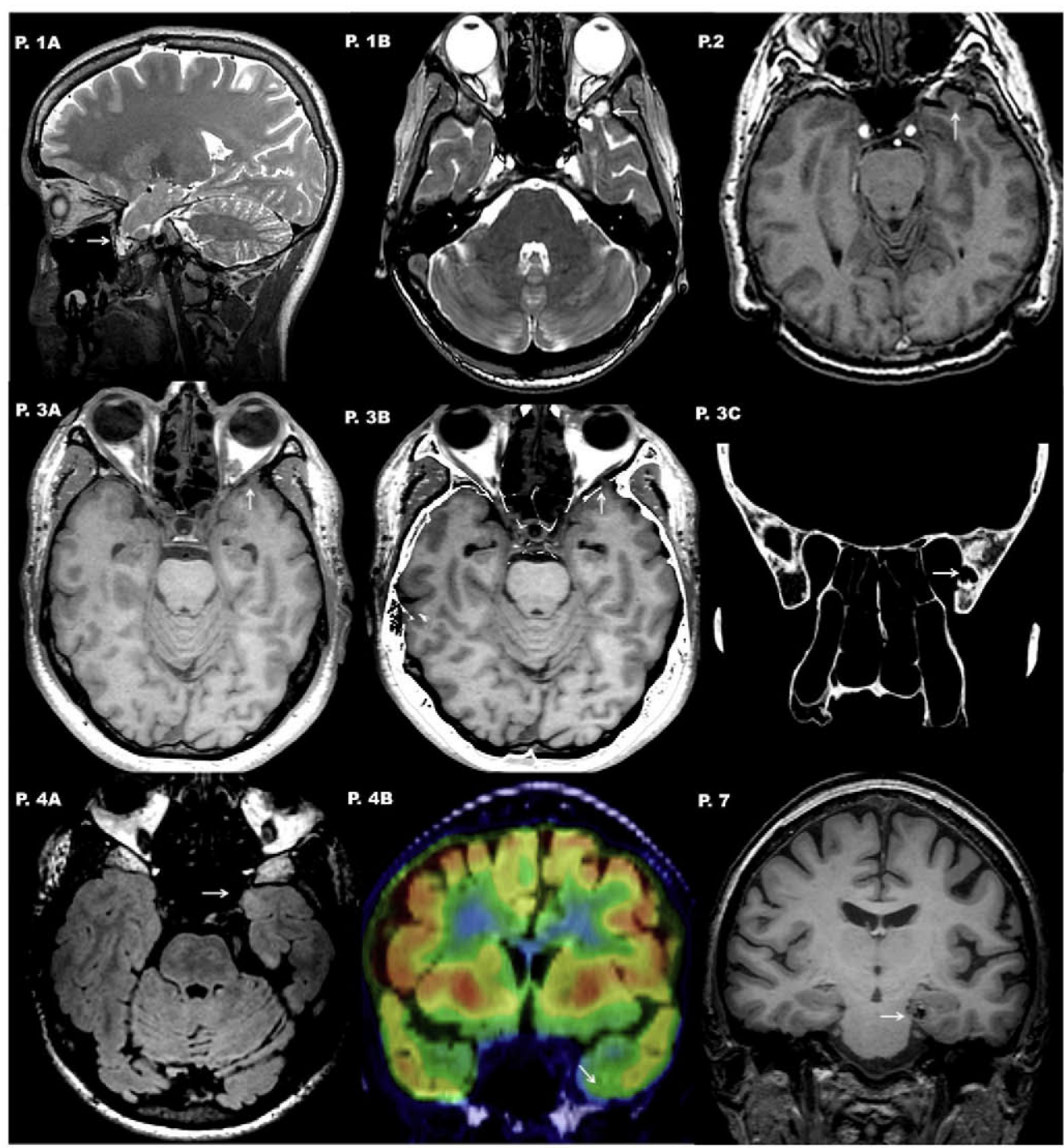

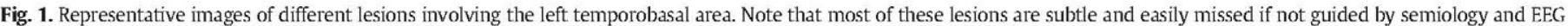

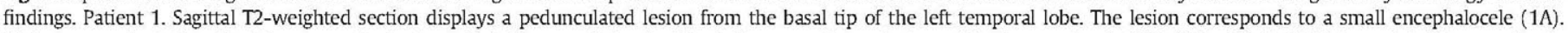

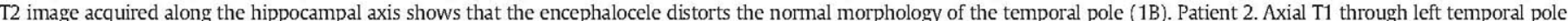

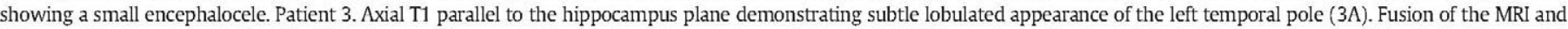

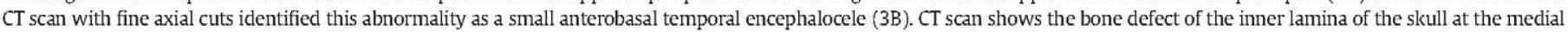

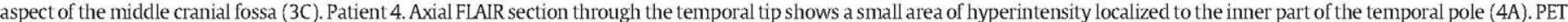

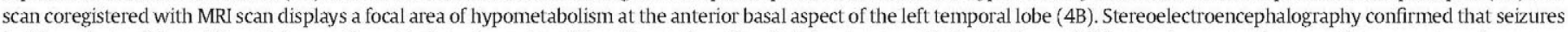

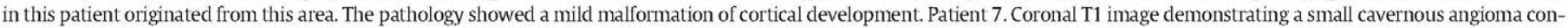
fined to the left anterior parahippocampal gyrus.

4 years of follow-up ( 4 to 9 years); one of them is currently awaiting surgery.

\section{Discussion}

Our data address the clinical characteristics of seizures arising from the temporopolar and the anterior temporobasal cortex. The most relevant observation in this case series is that aphasic seizures can result from small, left anterior circumscribed temporobasal lesions. Sequential analysis of ictal and postictal speech semiology showed a quite stereotyped pattern of language dysfunction, with global aphasia occurring during the ictal period and mixed transcortical aphasia during the postictal phase. Contrary to the established view that aphasia is only explained by extensive dysfunction in perisylvian language areas [15], our observations, in accordance with previous case reports [16,17], emphasize that anterior temporobasal lesions may also evoke speech manifestations. Furthermore, another distinctive feature of this type of seizure when compared with typical complex partial seizures caused by hippocampal sclerosis is that consciousness may not be impaired, as proved by lack of postictal amnesia. This is also supported by adequate ictal nonverbal reaction to sensory stimuli and lack of behavioral arrest or staring during the ictal period in all patients.

In our patients, lesions were located in an area expanding from the temporal pole to $4.5 \mathrm{~cm}$ posteriorly in the anterior-inferior temporal cortex. In this regard, recent studies have identified the temporal basal and polar cortex as critical for word comprehension and naming [4-6]. Similar to previous studies [6], baseline neuropsychological testing in a subsample of patients with left-sided lesions showed mild impairment in verbal and visual semantic tasks when compared with matched controls. These results are in line with a proposal suggesting that these areas constitute a convergence region that supports an activation of amodal representations for all semantic categories [6]. Thus, one possible explanation for the ictal and the postictal aphasia found in patients with left temporobasal lesions is that seizures transiently interrupt access to this part of the semantic network, thereby resulting in both speech arrest and comprehension deficits during the ictal phase and in semantic errors and word-finding difficulties during the recovery period. The fact that in two patients SEEG accurately located 
Neuropsychological data.

\begin{tabular}{|c|c|c|c|c|c|c|c|c|c|c|c|c|c|c|c|}
\hline & \multirow[t]{2}{*}{$\mathrm{P \# 1}$} & \multirow[t]{2}{*}{$P \# 2$} & \multirow[t]{2}{*}{$\mathrm{P} \# 3$} & \multirow[t]{2}{*}{$\mathrm{P} \# 4$} & \multirow[t]{2}{*}{$\mathrm{P} \# 5$} & \multirow[t]{2}{*}{$\mathrm{P} \# 7$} & \multirow[t]{2}{*}{$\mathrm{P} \# 9$} & \multirow[t]{2}{*}{ P\#10 } & \multirow[t]{2}{*}{$\mathrm{P} \# 11$} & \multicolumn{2}{|c|}{ Patients } & \multicolumn{2}{|c|}{ Controls } & \multirow[t]{2}{*}{$x^{2}$} & \multirow[t]{2}{*}{$\mathrm{p}$} \\
\hline & & & & & & & & & & Mean & $\mathrm{SD}$ & Mean & $\mathrm{SD}$ & & \\
\hline Age & 27 & 45 & 44 & 35 & 44 & 38 & 27 & 55 & 32 & 38.55 & 9.31 & 37.30 & 7.86 & 0.37 & n.s. \\
\hline Level of education (years) & 17 & 17 & 12 & 17 & 17 & 13 & 17 & 14 & 17 & 15.66 & 2.06 & 16.00 & 2.11 & 0.09 & n.s. \\
\hline \multicolumn{16}{|l|}{ Semantic tasks } \\
\hline 64-item naming test $t^{a, b, c}$ & 98.44 & 98.44 & 93.75 & 98.44 & 100 & 93.75 & 82.81 & 93.75 & 100 & 95.48 & 5.44 & 95.63 & 3.02 & 0.0 & n.s. \\
\hline Phil-naming test ${ }^{\mathrm{a}, \mathrm{c}}$ & 95.83 & 97.92 & 92.36 & 92.36 & 93.06 & 96.53 & 78.47 & 91.67 & 96.53 & 92.74 & 5.81 & 96.87 & 2.41 & 5.61 & $<.05$ \\
\hline Camel and Cactus ${ }^{\mathrm{a}, \mathrm{b}}$ & 92.19 & 87.50 & 87.50 & 89.06 & 75 & 82.81 & 89.06 & 93.75 & 89.06 & 87.33 & 5.55 & 92.81 & 3.47 & 5.25 & $<.05$ \\
\hline \multicolumn{16}{|l|}{ Fluency $^{\mathrm{b}}$} \\
\hline Birds & 18 & 8 & 11 & 8 & 6 & 12 & 6 & 11 & 9 & 10.77 & 4.15 & 16.00 & 4.08 & 6.84 & $<.01$ \\
\hline Breeds of $\mathrm{dog}$ & 17 & 16 & 9 & 6 & 4 & 7 & 6 & 7 & 10 & 8.44 & 3.78 & 13.00 & 5.21 & 7.05 & $<.01$ \\
\hline Types of boat & 9 & 10 & 12 & 15 & 4 & 11 & 10 & 7 & 10 & 11.22 & 5.38 & 10.70 & 2.40 & 0.06 & n.s. \\
\hline \multicolumn{16}{|l|}{ Verbal memory (WMS) } \\
\hline Verbal leamingd & 20 & 29 & 23 & 17 & n.a. & 27 & 18 & 22 & n.a. & & & & & & \\
\hline Verbal retention $^{\mathrm{d}}$ & 18 & 26 & 24 & 21 & n.a. & 24 & 18 & 21 & n.a. & & & & & & \\
\hline
\end{tabular}

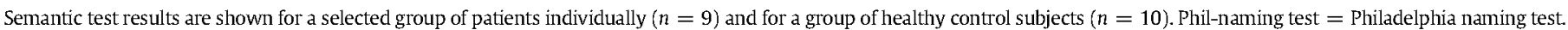

64-item naming test $=$ Cambridge 64-item naming task. WMS $=$ Wechsler Memory Scale-III. n.s. $=$ not significant. n.a. $=$ not available.

a Percentage of correct answers.

b Tests extracted from the Cambridge Semantic Battery.

c Stimuli shared by Cambridge naming test and Philadelphia naming test were presented only once.

d Standard score.

the epileptogenic zone at the anterior temporobasal cortex and two patients with left-sided temporal lesions eventually became seizure-free after surgery demonstrates that ictal aphasia can primarily originate in this brain area, instead of spreading from primary language areas (e.g., Wernicke's and Broca's areas). Supporting this observation, electrocortical stimulation of the BTLA, the area where the lesions described in this series were located, produces a wide range of speech manifestations in patients with epilepsy similar to that observed in our patients with left-sided lesions [1-3].

The paucity of literature regarding our observations may be explained by several reasons. Firstly, when language is impaired during a seizure, assessing level of awareness is difficult, and alteration of consciousness is assumed in most cases. In order to identify this type of seizure, recollection of ictal keywords could be misleading, as most of the patients will not recall the word because of primary impairment of language rather than a memory deficit. In this setting, evaluation of ictal nonverbal reaction to sensory stimuli and assessment of the patient's ability to recall ictal events postictally (such us the inability to speak and comprehend during the seizure) would be more appropriate to determine ictal awareness $[10,18,19]$. This observation might account for the fact that many seizures in our study were initially classified as CPS. Secondly, previous studies describing epilepsy secondary to lesions at the basal surface of the temporal lobe have not emphasized speech impairment as a salient feature [20-22]. This discrepancy may reflect the fact that epilepsy in some of these patients was caused by lesions extending to multiple gyri as well as by larger focal cortical dysplasias. The latter are commonly associated with a broader epileptogenic zone compared with that revealed on MRI, with ensuing seizures potentially associated with loss of awareness or another semiology that could mask speech manifestations. Thirdly, epilepsy in our patients was caused by small lesions that could have been missed at initial MRI reporting if not suspected [22]. Awareness of this association urged a more careful review of previous brain MR imaging and led to the finding of subtle lesions in the area of concern.

As this is a descriptive study, some limitation should be acknowledged. Our clinical and pathophysiologic findings are limited by the relatively small patient sample as well as the lack of confirming intracranial recordings and response to epilepsy surgery in all the patients studied. Nevertheless, accurate and prolonged video-EEG monitoring concordant with neuroimaging is considered to reduce the risk of biases in those cases not undergoing surgery [23]. In addition, striking clinical similarities between ictal behavior in our series and data obtained from neurophysiologic and functional imaging studies support our localization hypothesis. Because we did not include a comparison group of patients with hippocampal sclerosis, we cannot conclude that semantic memory impairment is only associated with left anterior temporobasal lesions. Therefore, it would be relevant to compare current results with those of patients with mesial TLE in order to determine the degree of specificity of semantic impairment observed in our group of patients.

\section{Conclusions}

Our study provides strong evidence that in addition to the classic language areas typically involved in speech disturbances, small, left anterior temporobasal lesions may cause aphasic seizures without impairment of consciousness and any other prominent manifestations. On the basis of our findings, recognition of this type of seizure should prompt detailed assessment of the structural integrity of the basal surface of the temporal lobe.

\section{Disclosure of conflicts of interest}

None of the authors has any conflict of interest to disclose. We all confirm that we have read the Journal's position on issues involved in ethical publication and affirm that this report is consistent with those guidelines.

\section{Author contributions}

All the authors were involved in drafting and revising the article.

\section{Acknowledgments}

This work was supported by the Fundacion INCE, Madrid, Spain and by a research grant from the Spanish Ministry of Science and Innovation (Grant SAF2011-27920) to IGM. CP is supported by the Spanish Ministry of Science and Education (AP2009-4131). PC is supported by a Ramon y Cajal Fellowship (RYC-2010-05748) and BS by project grant (SAF201127766) from the Spanish Ministry of Science and Innovation.

\section{References}

[1] Lüders H, Lesser RP, Hahn J, Dinner DS, Morris H, Resor $S$, et al. Basal temporal language area demonstrated by electrical stimulation. Neurology 1986;36:505-10. 
[2] Burnstine TH, Lesser RP, Hart Jr J, Uematsu S, Zinreich SJ, Krauss GL, et al. Characterization of the basal temporal language area in patients with left temporal lobe epilepsy. Neurology 1990;40:966-70.

[3] Lüders H, Lesser RP, Hahn J, Dinner DS, Morris HH, Wyllie E, et al. Basal temporal language area. Brain 1991;114:743-54

[4] Schwartz MF, Kimberg DY, Walker GM, Faseyitan O, Brecher A, Dell GS, et al. Anterio temporal involvement in semantic word retrieval: voxel-based lesion-symptom mapping evidence from aphasia. Brain 2009;132:3411-27.

[5] Sharp DJ, Scott SK, Wise RJ. Retrieving meaning after temporal lobe infarction: the role of the basal language area. Ann Neurol 2004;56:836-46.

[6] Lambon Ralph MA, Ehsan S, Baker GA, Rogers TT. Semantic memory is impaired in patients with unilateral anterior temporal lobe resection for temporal lobe epilepsy. Brain 2012;135:242-58

[7] Anonymous. Proposal for revised classification of epilepsies and epileptic syndromes. Commission on Classification and Terminology of the International League Against Epilepsy. Epilepsia 1989;30:389-99.

[8] Engel Jr J. Report of the IIAE classification core group. Epilepsia 2006;47:1558-68.

[9] Hillis AE. Aphasia. Progress in the last quarter of a century. Neurology 2007;69:200-13.

[10] Lux S, Kurthen M, Helmstaedter C, Hartje W, Reuber M, Elger CE. The localizing value of ictal consciousness and its constituent functions: a video-EEG study in patients with focal epilepsy. Brain 2002;125:2691-8.

[11] Hermann BP, Perrine K, Chelune GJ, Barr W, Loring DW, Strauss E, et al. Visua confrontation naming following left anterior temporal lobectomy: a comparison of surgical approaches. Neuropsychology 1999;1999(13):3-9.

[12] Patterson K, Nestor PJ, Rogers TT. Where do you know what you know? The representation of semantic knowledge in the human brain. Nat Rev Neurosci 2007;8: 976-87.
[13] Roach A, Schwartz MF, Martin N, Grewal RS, Brecher A. The Philadelphia naming test: scoring and rationale. Clin Aphasiology 1996;24:121-33.

[14] Adlam AI, Patterson K, Bozeat S, Hodges JR. The Cambridge Semantic Memory Test Battery: detection of semantic deficits in semantic dementia and Alzheimer's disease. Neurocase 2010;16:193-207.

[15] Trebuchon-Da Fonseca A, Guedj E, Alario FX, Laguitton V, Mundler O, Chauvel P, et al. Brain regions underlying word finding difficulties in temporal lobe epilepsy. Brain 2009;132:2772-84.

[16] Suzuki I, Shimizu H, Ishijima B, Tani K, Sugishita M, Adachi N. Aphasic seizure caused by focal epilepsy in the left fusiform gyrus. Neurology 1992;42:2207-10.

[17] Abou-Khalil B, Welch L, Blumenkopf B, Newman K, Whetsell Jr WO. Global aphasia with seizure onset in the dominant basal temporal region. Epilepsia 1994;35: $1079-84$.

[18] Ali F, Rickards H, Cavanna AE. The assessment of consciousness during partial seizures. Epilepsy Behav 2012;23:98-102.

[19] Cavanna AE, Rickards H, Ali F. What makes a simple partial seizure complex? Epilepsy Behav 2011;22:651-8.

[20] Mirandola L, Badawy RA, Saunders AM, McIntosh A, Berkovic SF, Jackson GD. Clinical features of seizures associated with parahippocampal/inferior temporal lesions compared to those with hippocampal sclerosis. Epilepsia 2010;51:1906-9.

[21] Pillay N, Fabinyi GC, Myles TS, Fitt G], Berkovic SF, Jackson GD. Parahippocampal epilepsy with subtle dysplasia: a cause of "imaging negative" partial epilepsy. Epilepsia 2009;50:2611-8.

[22] Abou-Hamden A, Lau M, Fabinyi G, Berkovic SF, Jackson GD, Mitchell LA, et al. Small temporal pole encephaloceles: a treatable cause of "lesion negative" temporal lobe epilepsy. Epilepsia 2010;51:2199-202.

[23] Kellinghaus C, Lüders HO. Frontal lobe epilepsy. Epileptic Disord 2004;6:223-39. 